\title{
Biosorption of Colour, Copper and Zinc in Textile Wastewater using Carbonized Orange Peels
}

\author{
${ }^{1}$ Kumaraiah, P. H., ${ }^{1}$ Karanth, P., ${ }^{2}$ Sobande, M. A., ${ }^{* 2}$ Adetoro, E. A. and ${ }^{2}$ Ojoawo, S. O. \\ ${ }^{1}$ Civil Engineering Department, NNAM Institute of Technology, Nitte-574110, Udupi District, Karnataka State, India. \\ ${ }^{2}$ Civil Engineering Department, Ladoke Akintola University of Technology, Ogbomoso, Oyo State, Nigeria. \\ *Corresponding Author E-mail: yemmieadyt@yahoo.com; Tel: +234-810-558-6254
}

Submitted on: 11/02/2021

Accepted on: $21 / 04 / 2021$

\begin{abstract}
Recently, low-cost adsorbents from sustainable sources are required for the remediation of textile wastewater. Carbonized Orange Peels (COPs) was utilized in remediating colour, Zinc and Copper from textile wastewater. The initial and final $\mathrm{pH}$, colour and trace metals' composition of the wastewater used were determined for the adsorption processes. Batch adsorption experiment was carried out on COPs and textile wastewater's mixture to find effects of COP's dosage, agitation, pH and contact time on the colour, Zinc and Copper's removal from the wastewater. The adsorption isotherms and kinetic studies were conducted using Langmuir, Freundlich, Pseudo-first-order and Pseudo-second-order models. Findings established that the optimum removal of colour, Zinc and Copper respectively occurred at an adsorbent dosage of 2.5, 0.5 and $3.0 \mathrm{~g} / 100 \mathrm{ml}, \mathrm{pH}$ of 10,4 and 2, rotating speed of 100, 250 and $250 \mathrm{rpm}$, contact time of 40, 60, and 40 mins. The adsorption isotherms revealed only copper adsorption as optimum and well fitted Langmuir isotherm. Pseudosecond-order kinetic model best suited adsorption data of the colour and metal ions with high correlation coefficient $\left(R^{2}\right)$ exceeding 0.95. Conclusively, COPs is effective in remediating the colour, copper and zinc from the wastewater, thus, recommended as suitable adsorbent for treatment of textile wastewater.
\end{abstract}

Keywords: Batch adsorption, Carbonized, Orange peel, Textile wastewater.

\section{Introduction}

Textile wastewater is a muddle of dyes, organic compounds, trace metals, total dissolved solids, grits, salts, surfactants, chlorinated compounds, chemical and biological oxygen demand; and in the colouring processes, the proportion of lost textile wastewater is fifty percentage of the dye owing to the insignificant levels of dye-fibre fixation (Mohan et al., 2007). Textile wastewater's discharge into the environment has become a critical matter for both environmental and aesthetical reasons. It may be mutagenic, basically carcinogenic and lead to severe damages such as allergy, brain, dermatitis, skin discomfort, kidney malfunction, liver, malfunction of human's central nervous and reproductive system (Hatch, 2003). Furthermore, the coloured wastewater is extremely poisonous to the aquatic environment; they interfere in the light transmission and affect the biological metabolism activities, thereby causing ecosystem imbalances for aquatic communities (Pereira \& Arruda 2003; Noorozi and Sorial, 2013).

Textile wastewater is normally trained into very close drains which later find its way to the nearby lagoons, ponds, rivers, stagnant or stream. That kind of disposal of wastewater can result in impairment to the quality of the aesthetic and biological heterogeneity of environment, aquatic ecosystem, receiving water bodies. Due to these cataclysmic effects, it is very significant to ascertain distinct ways of treating this wastewater before being discharged into water bodies. In the world of today, Nigeria is one of the major consumers and producers of citrus fruits especially orange, while 
the orange (juices) were consumed as fantabulous means of vitamin $\mathrm{C}$; its peels are disposed and send to garbage as under-utilised materials without taking care of the environment and also not considering any preventive measure to exclude the percolation of these pollutants into the underlying water channels. It is therefore very important and essential to find meaningful applications for these peels as its generation is on the increase nowadays and poses a very serious environmental concern (Akinhanmi et al., 2020). As a result, orange peel as agro-waste is suggested to be developed into alternative and favourable adsorbent for remediation of textile wastewater.

In the recent past, a number of treatment technologies such as coagulation/flocculation (Vandevivere et al., 1998), chemical oxidation (Salem, 2001), ozonation (Baban et al., 2003), ion exchange process (Yu et al., 2001), solvent extraction (Lee et al., 2000), degeneration of photo catalysis (Tanaka et al., 2000) and adsorption process (Allen and Koumanova, 2005) have been adopted for remediation of wastewater. These treatment technologies are not affordable, inefficient and large residues are produced. Over the years, the activated carbon usage in adsorption technique has been substantiated as a very efficacious method of treating textile wastewater (Akinhanmi et al., 2020). The high adsorption efficiency of activated carbon, powdery or granular mode made it almost extensively utilised adsorbent for organic compounds (Alyuz and Velis, 2009). Yet, high cost and residue generation are certain challenging factors of using activated carbon adsorbents in water pollution control; hence there have been efforts in the direction of developing alternative low cost ones.

The use of agro-wastes as adsorbent presently receives more attention due to their accessibility, convenient chemical alteration, existence of good structure of porous, less disposal problem after adsorption, low cost, proficient adsorption capacity, proportionate high content of fixed carbon, and quick renewal. Agro-wastes adsorbents are economical, efficient and safe at removing various pollutants like trace metals, COD, phenol, and dyes from industrial wastewater (Salleh et al., 2011). Much more recently, activated carbon utilization in adsorption process has been substantiated to be a commonly employed and an effective technique for textile wastewater's treatment (Alyuz and Velis, 2009). The activated carbon from commercial source is still a costly material and for this reason, the search for economical and eco-friendly adsorbent for dye remediation in wastewater is highly essential. Locust bean pod (Bello et al., 2019) and lemon grass leaf (Ahmad et al., 2020 \& 2021) among others have been studied and reported as agro-waste adsorbents used in treatment of textile wastewater. In an earlier research, the ability of orange peel to remove acid dye (Sivaraj et al., 2001), nickel (Gonen and Serin, 2012), cadmium (Akinhanmi et al., 2020) etc. from aqueous solutions were investigated.

Basically, Orange peel has water - soluble colloidal carbohydrates, hemi-cellulose, complex polymer fibers, green pigment with some hydrocarbons of low molecular weight (Liang et al., 2010). The peels are cheap, non-dangerous, non-poisonous, degradable and environmentally favourable biosorbents in wastewater treatment. This study was performed to investigate removal efficiency of colour Copper $(\mathrm{Cu})$ and Zinc $(\mathrm{Zn})$ from textile wastewater using carbonized orange peels (COPs). The key objectives are to determine initial absorbance and concentration, optimum values of rotating speed (in revolutions per minute, $\mathrm{rpm}$ ), retention time, adsorbent's dosage and $\mathrm{pH}$ variables on percentage removal of colour, $\mathrm{Zn}$ and $\mathrm{Cu}$ from textile wastewater in a bid to assess the overall adsorbent efficiency. 
LAUTECH Journal of Civil and Environmental Studies

Volume 6, Issue 2; May, 2021

\section{Materials and Methods \\ Preparation of Samples}

The preparation of both the orange peel adsorbent and the wastewater samples are as follows:

(i) The raw adsorbent: Fresh oranges were purchased from Ile-Epo market in Agbado Oke-Odo Local Government Area of Lagos State, Nigeria. Oranges were washed and peeled. The peels were washed under sterilized water to get rid of any dirt and undesirable elements. They were aseptically cut into little pieces for comfortable drying, and then dried in an oven at $100 \pm 2{ }^{\circ} \mathrm{C}$ temperature for $24 \mathrm{hrs}$ (Ojoawo et al., 2018). The dried pieces were powdered using mixer grinder and sieved using BS Sieve 10 (i.e. $2.00 \mathrm{~mm}$ ) for uniform particle size and were stockpiled in air tight container. The prepared orange peel powder was calcined in a muffle furnace (Carbolite CWF 1200) at $300 \pm 5{ }^{\circ} \mathrm{C}$ for $2 \mathrm{hrs}$ at the Federal Institute for Industrial Research, Oshodi, Lagos, Nigeria following procedures of Malik (2004). The Carbonized Orange Peel (COP) powder was cooled to room temperature, washed with sterilized water till constant $\mathrm{pH}$ of 7 is attained and then oven dried at 105 $\pm 5^{\circ} \mathrm{C}$. The COP otherwise called adsorbent was sieved using BS Sieve 40 (i.e. $0.425 \mathrm{~mm}$ ) and kept in a desiccate for future use.

(ii) Wastewater preparation: Fresh sample of textile wastewater was collected from the AdireKampala market local dye industry at Itoku, Abeokuta, Ogun State of Nigeria. The samples were fetched according to the standards stipulated in Ojoawo and Udayakumar (2016) and taken directly to the laboratory for experiments. Distilled water was obtained from Food Technology Department, LAUTECH, Ogbomoso, Nigeria. Hydrochloric acid $(\mathrm{HCl})$ and Sodium hydroxide $(\mathrm{NaOH})$ were obtained from Labtrade Chemicals, Idi - Araba, Ogbomoso, Nigeria. The equipment used includes pH meter, UV spectrophotometer, and Atomic Absorption Spectrophotometer (AAS).

\section{Adsorption experiment}

Adsorption experiment was carried out for assessment of the efficacy of the prepared adsorbent in remediating dye wastewater. Batch adsorption experiment at room temperature was adopted to find the effects of adsorbent's dosage $(0.5,1.0,1.5,2.0,2.5$ and 3.0 gram) at constant agitation rate (150 $\mathrm{rpm}$ ), contact time (60 mins.) and $\mathrm{pH}(7.0)$ on the remediation of colour, $\mathrm{Zn}$ and $\mathrm{Cu}$ from textile wastewater. The $\mathrm{pH}$, colour and presence of trace metals in the textile wastewater were determined before and also in the filtrate after the adsorption processes. The $\mathrm{pH}$ of sample was analyzed using a digital $\mathrm{pH}$ meter (Model KL-031) and adjusted as required using either $0.1 \mathrm{M}$ of $\mathrm{HCl}$ or $\mathrm{NaOH}$ solution. The colour and the presence of $\mathrm{Zn}$ and $\mathrm{Cu}$ were established using UV spectrophotometer and AAS respectively. The Water Resources Laboratory of the Civil Engineering Department, LAUTECH, Ogbomoso, Nigeria was used for the experiments and analyses. Each of the experiments was carried out thrice and the optimum value of the adsorbent dosage determined which was then used for subsequent experiments.

(i) Variation of $\mathrm{Zn}^{2+}$ and $\mathrm{Cu}^{2+}$ removal from textile wastewater with agitation speed, contact time, absorbent's dosage and $\mathrm{pH}$ : Subsequently, solutions from the above experiments were filtered using Whatman no. 45 filter paper in preparation for determination of $\mathrm{Zn}$ and $\mathrm{Cu}$ concentrations in the filtrate. The $\mathrm{Zn}$ and $\mathrm{Cu}$ concentrations of each sample was analysed by AAS of the Central Research Laboratory, LAUTECH, Ogbomoso, Nigeria. The amount of adsorbed metals was established with Eq. (1) and the removal efficiency determined through computation of the percentage adsorption using Eq. (2) (Song et al., 2014; Ojoawo et al., 2018).

$$
\text { The amount of adsorbed metal }(\mathrm{qe})=\frac{(\mathrm{Co}-\mathrm{Ce}) \mathrm{V}}{\mathrm{m}}
$$




$$
\text { Percentage removal }=\frac{(\mathrm{Co}-\mathrm{Ce}) 100}{\mathrm{Co}}
$$

Where qe is the adsorption capacity at equilibrium ( $\mathrm{mg}$ of ions/g of orange peels), $\mathrm{V}$ is the volume of the aqueous solution $(\mathrm{mL}), \mathrm{Co}$ is the concentration before adsorption $(\mathrm{mg} / \mathrm{L}), \mathrm{Ce}$ is the equilibrium concentration after adsorption $(\mathrm{mg} / \mathrm{L})$ and $\mathrm{m}$ is the mass in gram of the adsorbent.

(ii) Variation of colour removal from textile wastewater with adsorbent's dosage, optimum agitation speed and time: $100 \mathrm{ml}$ of textile wastewater was maintained at $\mathrm{pH}$ of 7.0 in a reagent bottles (250 $\mathrm{ml}$ ) and variants dosage of 0.5, 1.0, 1.5, 2.0, 2.5 and 3.0 gram of adsorbent was added to it. The solutions were then kept in rotary machine at the optimum agitation speed for the optimum time to enhance effectual mixing. Then the reaction mixtures in the reagent bottles were maintained undisturbed for $1 \mathrm{hr}$. in other to allow settlement of the precipitation formed. This precipitate was segregated from the mix by filtration through $0.45 \mu \mathrm{m}$ Whatman filter paper. Initial sample without adsorbent was used as control. The filtrate was studied for percentage colour removal and the optimum dosage for colour removal was determined.

(iii) Variation of colour removal from textile wastewater with $\mathrm{pH}$, optimum agitation, time and adsorbent's dosage: The textile wastewater was examined at different $\mathrm{pH}$ of 2.0, 4.0, 6.0, 8.0, and 10.0. The optimum dosage of adsorbent was added to $100 \mathrm{ml}$ of the textile wastewater in the 250 $\mathrm{ml}$ reagent bottles. The solutions were kept in rotary machine at the optimum RPM for the optimum time to enhance effectual mixing. The bottles having retorted mixed substance was left untroubled for $1 \mathrm{hr}$. to enable settlement of precipitation formed. The formed precipitate was segregated from the mix using $0.45 \mu \mathrm{m}$ Whatman filter paper (i.e. filtration). Initial sample without adsorbent was used as control. The filtrate was examined for percentage colour removal. \% colour removal was determined using the initial and final absorbance values (i.e. before and after treatment values) for the textile wastewater samples and thus, Standard calibration curve was prepared. The $\%$ colour removal was established by the formula in Eq. (3) (Javaid, 2013).

$$
\% \text { Colour removal }=\frac{(\mathrm{Co}-\mathrm{Ce}) \times 100}{(\mathrm{Co})}
$$

(iv) Variation of colour removal from textile wastewater with agitation: $100 \mathrm{ml}$ of the textile wastewater was maintained at $\mathrm{pH} 7.0$ inside $250 \mathrm{ml}$ reagent bottles and 1 gram of adsorbent was added to it. The solution was then kept in rotary machine at variant speeds of 50, 100, 150, 200 and $250 \mathrm{rpm}$ for $60 \mathrm{~min}$ in each case to enhance effectual mixing and causes formation. The reagent bottles housing retort mixture were being put in uninterrupted condition for 1 hour to allow the settlement of the formed precipitation. The settled precipitate was separated through its filtration through $0.45 \mu \mathrm{m}$ Whatman filter paper. Initial sample without adsorbent served as control. Filtrates were analysed for the maximum concentration of dye absorbed and percentage colour removal, while the optimum agitation speed in rpm was also determined.

(v) Variation of colour removal from textile wastewater with contact time: The solutions were prepared as in (iv) then kept in a rotary machine at the optimum agitation for a variant time of 20 , 40, 60, 80 and 100 minutes to enhance effectual mixing and causes formation. Standard adsorption procedure was followed and the settled precipitate segregated from the mix by filtration. All the samples at the varying contact time were analyzed and compared with the initial sample to determine the $\%$ removal of dye and the effects of contact time. The optimum time for the colour removal percentage was determined. 
LAUTECH Journal of Civil and Environmental Studies

Volume 6, Issue 2; May, 2021

Tests

(i) Fourier Transform Infrared (FTIR) characterization of the adsorbent: The functional groups of the Orange peel biosorbent and adsorbent were determined by FTIR using Infrared Spectrophotometer (BUCK M530 model series) at the Central Research Laboratory of LAUTECH, Ogbomoso, Nigeria. Infrared Spectrophotometer is an exceptionally mighty instrument for distinguishing the functionalities' presence e.g. alkane, aromatic compounds, amino compounds, Carbonyl, Hydroxyl etc. The molecule's vibration spectra are observed to be a distinctive physical property. The most useful region of the infrared radiation extends from above 2.5 to 16 microns ( 1 micron $=1$ micrometer $=10-6$ meter $)$. The wave number of a particular radiation is the number of waves per centimeter, which is simply one divided by the wavelength $(\lambda)$ in centimeter (Hassan and Abiola, 2018).

(ii) UV Spectrophotometer: Generally, the dye wastewater's concentration was established spectrophotometrically at maximum wavelength of 580 with UV-vis spectrophotometer with the initial absorbance of 0.320 Abs.

(iii) Atomic Absorption Spectrophotometer $(A A S)$ : The wastewater $(10 \mathrm{ml})$ and nitric acid $(10 \mathrm{ml}$, acting as a catalyst) was carefully mixed in a $50 \mathrm{ml}$ beaker and heated for 30 minutes at $100^{\circ} \mathrm{C}$ inside fume cupboard. Sterilized water added to the cooled mixture after being removed from the fume cupboard in other to make it up to $100 \mathrm{ml}$, filtered and the filtrate was analysed using AAS. The filtrate samples from the batch adsorption experiments were initially digested in other to breakdown their elements' complexities. The AAS with model number PG-990 of the College of Agriculture, University of Osun, Ejigbo Campus, Osun State, Nigeria was used (Ojoawo and Udayakumar, 2016).

\section{Adsorption Isotherm}

Adsorption isotherm is the relationship established by determining the quantity of material adsorbed as concentration of adsorbent basis at steady temperature. Quantity of adsorbed adsorbate is nearly continuously normalized by the adsorbent's mass for various layers' comparison.

(i) Langmuir Isotherm: It based on the occurrence of adsorption at particular homogeneous sites of the adsorbent. Adsorption's monolayer is adopted on the surface of the concerned adsorbent. It is as presented in Eq. (4) (Langmuir, 1918).

$$
\frac{\mathrm{C}_{\mathrm{e}}}{\mathrm{q}_{\mathrm{e}}}=\frac{1}{\mathrm{q}_{\mathrm{m}}} \cdot \frac{1}{\mathrm{~K}_{\mathrm{L}}}+\frac{\mathrm{C}_{\mathrm{e}}}{\mathrm{q}_{\mathrm{m}}}
$$

Where qe is adsorbed concentration at equilibrium $(\mathrm{mg} / \mathrm{g})$, qm is maximum capacity of adsorbent for adsorbate corresponding to the complete monolayer coverage $(\mathrm{mg} / \mathrm{g}), \mathrm{Ce}$ is concentration at equilibrium ( $\mathrm{mg} / \mathrm{L})$ and $\mathrm{KL}$ is Langmuir isotherm constant associated with energy of adsorption.

The Langmuir constants qm and KL are calculated from the slope and intercept of plot between 1/qe versus $1 / \mathrm{Ce}$. Separation factor $\left(\mathrm{R}_{\mathrm{L}}\right)$, which shows the adsorption efficiency was calculated using Eq. (5).

$$
\mathrm{R}_{\mathrm{L}}=\frac{1}{1+\mathrm{K}_{\mathrm{L}} \mathrm{Co}}
$$


The value of $\mathrm{R}_{\mathrm{L}}$ equals $>1,1,0<\mathrm{R}_{\mathrm{L}}<1$ and 0 means the adsorption is linear, unfavourable and favourable and irreversible respectively (Chen and Zhao, 2009; Farooq et al., 2010).

(ii) Freundlich Isotherm: It expatiates on the correlation between perfect and non-perfect adsorption with its application to heterogeneous surface while there is an interaction among the molecules adsorbed. Its empirical formula is presented in Eq. (6) (Freundlich and Heller, 1939).

$$
\log q_{e}=\log K_{f}+\frac{1}{n f} \log C_{e}
$$

The plot of Log qe versus Log Ce will give the slope $1 / \mathrm{n}$ and intercept $\mathrm{Kf}\{(\mathrm{mg} / \mathrm{g}) /(\mathrm{L} / \mathrm{g}) \mathrm{n}\}$. Kf is the Freundlich constant related to adsorption intensity of adsorbents (mg/g) and $\mathrm{n}$ is the Freundlich exponent. Here, $\mathrm{Kf}$ and $\mathrm{n}$ are defined as the constants for the adsorption capacity and intensity of adsorption respectively. The slope (value of $1 / \mathrm{n}$ ), which always lie between 0 and 1 is a measure of adsorption intensity. If $1 / \mathrm{n}=1$ then this shows that the existing partition between the two phases are independent of the concentration. If value of $1 / \mathrm{n}$ is less than one, it depicts a normal adsorption, i.e an adsorption through chemical process). On the other hand, the value of $1 / \mathrm{n}$ being greater than one denotes cooperative adsorption, passing through a physical process (Matouq et al., 2015). Meanwhile if $\mathrm{n}$ however lie between one and ten it is an indication of a favourable adsorption process.

\section{Adsorption kinetics}

There is need for kinetic to facilitate adsorption systems' design and rate of reaction's control. The orange peel adsorption data can be analysed by kinetic studies that will result in determination of the capable adsorption mechanisms. Pseudo-first and pseudo-second order kinetic models were used to explain the adsorption processes in this study, which hinges on the physicochemical attributes of the adsorbent.

(i) Pseudo-first order kinetic model: It is broadly expressed in linear form according to Lagergren as presented in Eq. (7) (Markandeya et al., 2015, Farhan et al., 2012).

$$
\log \left(q_{e}-q_{t}\right)=\log \left(q_{e}\right)-\frac{K 1}{2.303} t
$$

The $\mathrm{K}_{1}$ and qe were evaluated from slope and intercept of straight line of plot Log (qe - qt) and $\mathrm{t}$. (ii) Pseudo-second order kinetic model: It is premised on adsorption capacity of adsorbate layers employed in analysing chemisorption's kinetics rate. It is utilised in a linear form of Eq. (8).

$$
\frac{t}{q_{t}}=\frac{1}{K_{2}\left(q_{e}\right)\left(q_{e}\right)}+\frac{1}{q_{e}} t
$$

The $\mathrm{K}_{2}$ and qe were evaluated from slope and intercept of straight line of plot $\mathrm{t} / \mathrm{qt}$ and $\mathrm{t}$. The fixed rate of adsorption of pseudo-first and second order kinetic models are $\mathrm{K}_{1}$ and $\mathrm{K}_{2}$, respectively, qt is the quantity of colour or metal adsorbed at particular time $t$ (minute), qe is the quantity of colour or metal adsorbed at equilibrium. 
LAUTECH Journal of Civil and Environmental Studies

Volume 6, Issue 2; May, 2021

\section{Results and Discussion}

FTIR characterization results of the adsorbent: Figure 1 portrays the functional groups of the orange peel sample using FTIR. Transmittance peaks at 3355 and 3239 1/cm shows the intra-molecular O$\mathrm{H}$ bonds while the bands at 2832, 2801, $27071 / \mathrm{cm}$ shows the asymmetric and symmetric $\mathrm{C}-\mathrm{H}$ respectively. The free carbonyl group $(\mathrm{C}=\mathrm{O})$ was seen at $17811 / \mathrm{cm}$ while the $\mathrm{C}=\mathrm{C}$ aromatic of the orange peel sample was seen at 1558.1. The $\mathrm{C}-\mathrm{H}$ bend vibrations were shown at 1407, 1268 and $12101 / \mathrm{cm}$ respectively. The increased boiling points in comparison to their parent alkanes was due to the presence of an - $\mathrm{OH}$ group alcohol. The covalent bond of $\mathrm{C}-\mathrm{H}$ bond portrays sharing of carbon in its outer valence electrons with hydrogens. The polarity of carbonyl group, $\mathrm{C}=\mathrm{O}$ bonded compounds increase both the melting and boiling points (Hassan and Abiola, 2018). All of these results are pointing to strong bonding characteristics of the orange peel adsorbent.

The initial absorbance and concentration of colour and metals in the textile wastewater sample: The initial $\mathrm{pH}$ of the textile wastewater is 10.0 at maximum wavelength of 580 with UV spectrophotometer and absorbance of 0.320 Abs. The selected trace metal (Zinc $-\mathrm{Zn}^{2+}$ and Copper $-\mathrm{Cu}^{2+}$ ) analysis as carried out on the dye sample detected an appreciable concentration of $\mathrm{Zn}^{2+}$ $(0.2456 \mathrm{mg} / \mathrm{L})$ and $\mathrm{Cu}^{2+}(0.2392 \mathrm{mg} / \mathrm{L})$.

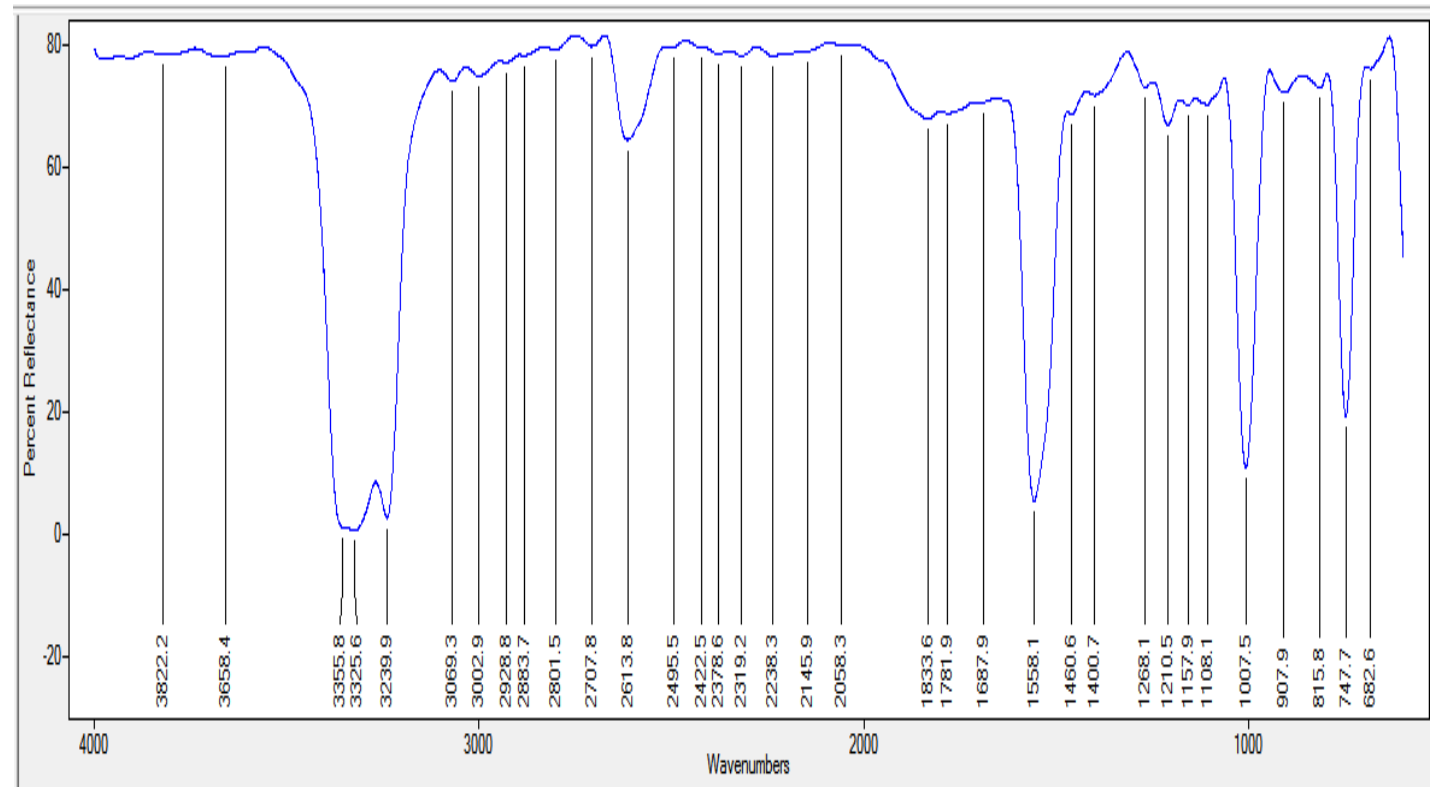

Figure 1. FTIR analysis Results on the Orange peel adsorbent

Effect of rotating speed on percentage removal of Colour, Zinc and Copper: The variation of colour, Zinc $\left(\mathrm{Zn}^{2+}\right)$ and Copper $\left(\mathrm{Cu}^{2+}\right)$ removed from textile wastewater with reference to rotating speed (in $\mathrm{rpm}$ ) are represented in Figure 2. Maximum removal of colour, $\mathrm{Zn}^{2+}$ and $\mathrm{Cu}^{2+}$ values were 41.56, 90.47 and $78.97 \%$ respectively, which occured at optimum values of $100 \mathrm{rpm}$ for colour and 250 rpm for both $\mathrm{Zn}^{2+}$ and $\mathrm{Cu}^{2+}$ as indicated by the circle on each of the graphs. From the obtained results, it could be seen that the percentage of colour removed increases sharply as the rotating speed increased in the first $100 \mathrm{rpm}$ perhaps as a result of enormous number of sites initially vacated. The removal efficiency later decreased with the increasing rotating speed, which indicated that there was no increase in colour removed with additional increase in the rotating speed. Initially, there was rapid removal percentages of $\mathrm{Zn}^{2+}$ and $\mathrm{Cu}^{2+}$ and also increased with contact time. This could be due 
to amount of active porous site available and the maximum concentration of $\mathrm{Zn}^{2+}$ and $\mathrm{Cu}^{2+}$ in the solution, thus enhances the maximization of $\mathrm{Zn}^{2+}$ and $\mathrm{Cu}^{2+}$ adsorption on adsorbent surface. Additional rotation makes available the vigour required to transport the $\mathrm{Zn}^{2+}$ and $\mathrm{Cu}^{2+}$ from the whole of the solution to the adsorbent's active sites through reduction of the resistance to mass transfer between adsorbent and whole phase as expressed by Salem (2001) and Malik (2004).

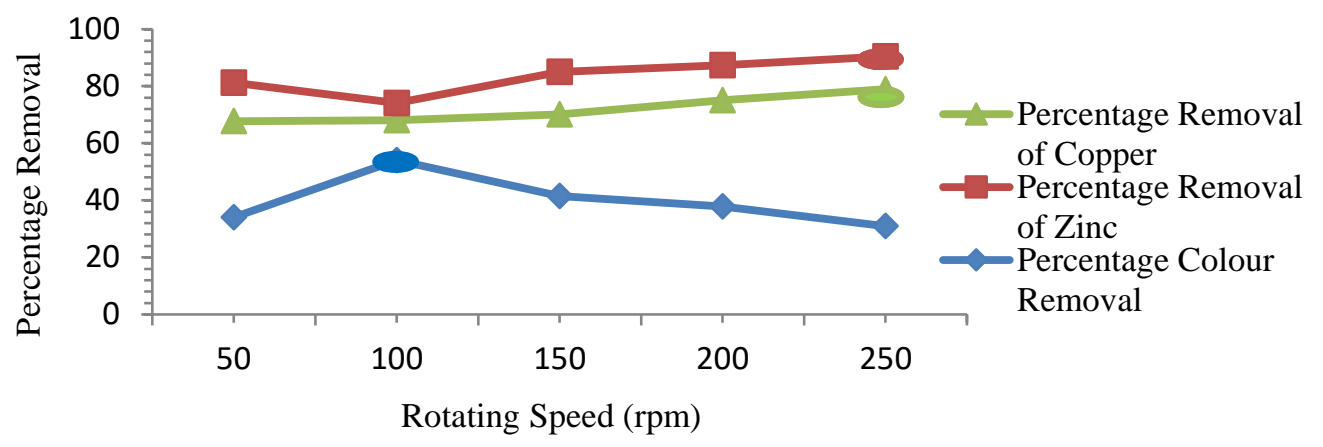

Figure 2. Effect of rotating speed on percentage removal of Colour, $\mathrm{Zn}$ and $\mathrm{Cu}$

Effect of contact time on percentage removal of Colour, Zinc and Copper: Variations of colour, Zinc $\left(\mathrm{Zn}^{2+}\right)$ and Copper $\left(\mathrm{Cu}^{2+}\right)$ removal from dye wastewater with time at optimum agitation speed of $100 \mathrm{rpm}$ for colour and $250 \mathrm{rpm}$ for $\mathrm{Zn}^{2+}$ and $\mathrm{Cu}^{2+}$ respectively are shown Figure 3 . The maximum colour, $\mathrm{Zn}^{2+}$ and $\mathrm{Cu}^{2+}$ removal of 50.31, 93.85 and $72.82 \%$ occurs at optimum time of 40,60 and 40 minutes respectively. The percentage of colour removal as a function of time indicated that, the percentage removal increased swiftly from the contact time of 20 - 40 minutes and decreased promptly as the contact time increased. This can be explained by the fact that initially, the quantity of sites on the surface is very large which allows adsorption to take place very easily. But with the passage of time, the active sites get saturated thereby reducing the rate at which adsorption occurs. It was noted that the optimum contact time of 40 minutes corresponds to the optimum contact time of Copper. Nonetheless, variation was observed among the percentage removal of $\mathrm{Zn}^{2+}$ and $\mathrm{Cu}^{2+}$.

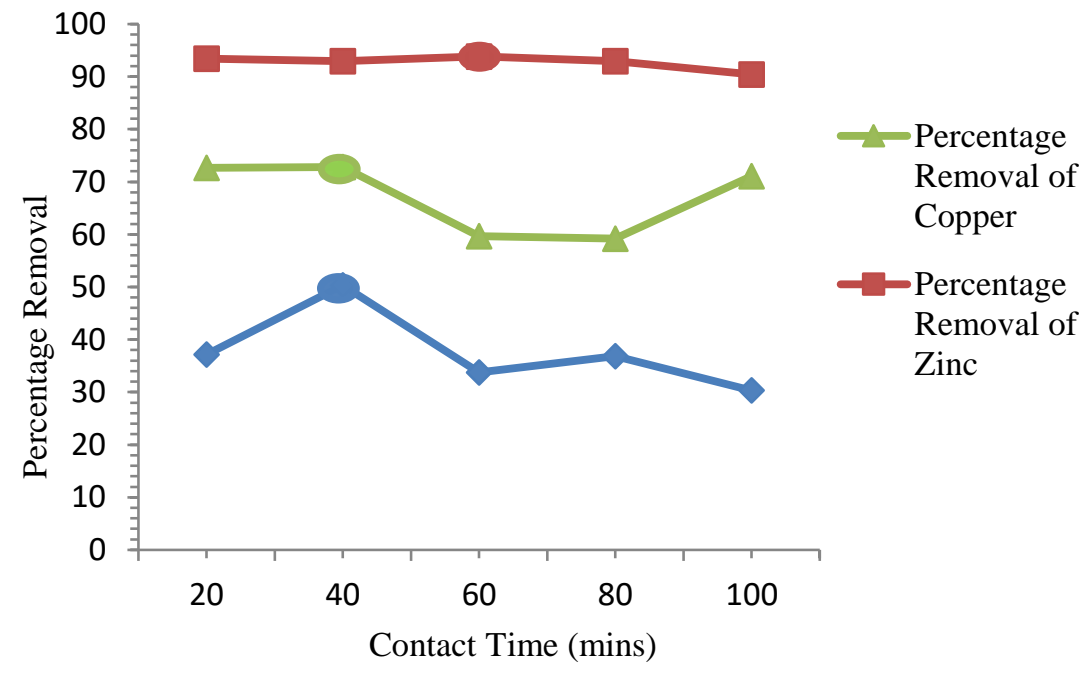

Figure 3. Effect of contact time on percentage removal of Colour, Zinc and Copper

Though, beyond the optimum contact time of the metals, further increase in contact time has no significant effect on the metal removal. This could be attributed to the accumulation of metal ions on the vacant sites or the solution itself is saturated, so increase in the rate of adsorption ceases (AsmaHanif et al., 2009). Therefore, further increase in contact time did not enhance the metal 
LAUTECH Journal of Civil and Environmental Studies

Volume 6, Issue 2; May, 2021

removal and thus, the optimum retention time is selected as reported by Salem (2001), Akinhanmi et al. (2020). The findings are also corroborated by Ojoawo and Udayakumar (2016).

Effect of adsorbent's dosage on percentage removal of Colour, Zinc and Copper: Variations of colour, Zinc and Copper $\left(\mathrm{Zn}^{2+}\right.$ and $\left.\mathrm{Cu}^{2+}\right)$ removal from dye wastewater with adsorbent dosage (carbonized orange peel) at optimum agitation of $100 \mathrm{rpm}$ for colour and $250 \mathrm{rpm}$ for $\mathrm{Zn}^{2+}$ and $\mathrm{Cu}^{2+}$ and optimum contact time of 40,60 and 40 mins respectively are shown in Figure 4. The maximum efficiencies of the adsorbent for colour, $\mathrm{Zn} 2+$ and $\mathrm{Cu} 2+$ removal of 70.93, 99.84 and $75.75 \%$ occurs at optimum dosage of 2.5, 0.5 and $3.0 \mathrm{~g}$ respectively. Adsorbent's dosage plays a fundamental role in adsorption process (Salleh et al., 2011). The percentage removal of colour was found to increase as the adsorbent's dosage increases. This could be attributed to the increase in surface area and amount of active sites in the adsorbent. Moreover, with further increase, there was an observed decrease in the percentage removal of colour due to an increase in adsorbent dosage beyond maximum adsorption capacity which might be due to the congestion of adsorbent particles beyond the optimum dose (Garg et al., 2004). In relation to metals, it was observed that $\mathrm{Zn}^{2+}$ has virtually equal percentage removal values with increasing adsorbent's dosage from 0.5 to $3.0 \mathrm{~g}$ while $\mathrm{Cu}^{2+}$ metals displayed varying removal efficiencies with dosage. This observation is in relation to Ojoawo and Udayakumar (2016) findings on remediation and adsorption studies of lead and copper in fresh foundry wastewater using AC-250.

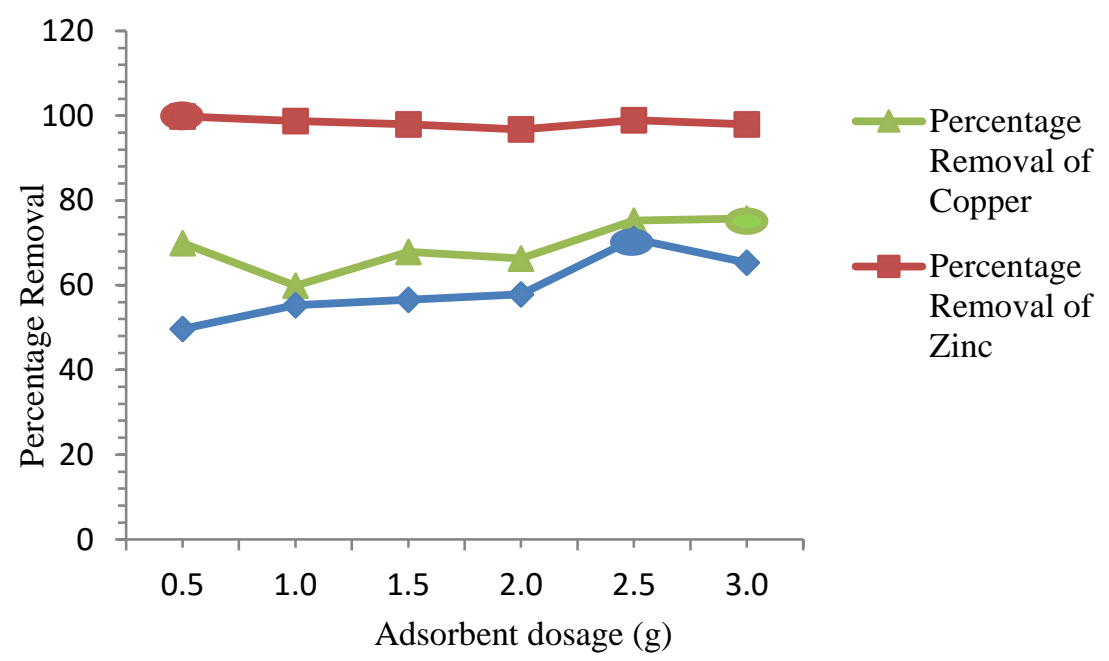

Figure 4. Effect of adsorbent dosage on percentage removal of Colour, Zinc and Copper

Effect of pH on percentage removal of Colour, Zinc and Copper: Variations of colour, $\mathrm{Zinc}\left(\mathrm{Zn}^{2+}\right)$ and Copper $\left(\mathrm{Cu}^{2+}\right)$ removal from dye wastewater with $\mathrm{pH}$ at optimum agitation of $100 \mathrm{rpm}$ for colour and 250 for $\mathrm{Zn}^{2+}$ and $\mathrm{Cu}^{2+}$, optimum time of 40,60 and 40 mins. respectively and at optimum dosage of 2.5, 0.5 and $3.0 \mathrm{~g}$ respectively are shown in Figure 5. The original $\mathrm{pH}$ of the dye wastewater has a very noteworthy effect on the adsorbent surface characteristics as well as the degree at which the dye molecules ionize and thus, it becomes utmost to examine the influence that $\mathrm{pH}$ has on the adsorption process (Salleh et al., 2011). The maximum colour, $\mathrm{Zn}^{2+}$ and $\mathrm{Cu}^{2+}$ removal of $87.18,99.76$ and $93.81 \%$ occurs at optimum dye sample $\mathrm{pH}$ of 10,4 and 2 respectively. In the trials, as the $\mathrm{pH}$ of the solution increase the removal efficiency of the colour also increases. The higher adsorption at $\mathrm{pH} 10$ could be due to interaction between the positively charged dyes cations and the bio-active ingredients that may be present in the adsorbent.

Moreover, the $\mathrm{pH}$ is one of the main variable parameters in adsorption process which affects the removal efficiency of $\mathrm{Zn}^{2+}$ and $\mathrm{Cu}^{2+}$. It was observed that $\mathrm{Zn}^{2+}$ has virtually equal percentage removal values with increasing $\mathrm{pH}$ from 2 to 10 while $\mathrm{Cu}^{2+}$ metals displayed varying removal 
efficiencies with $\mathrm{pH}$. The noted percentage removal of metal ions may be attributed to the fact that the adsorbent surface is already de-protonated and is negatively charged, hence attraction between the positively metal cations occurred which increases the availability of $\mathrm{Zn}^{2+}$ and $\mathrm{Cu}^{2+}$ for adsorption as corroborated by Lohani et al., (2008); Adetoro and Ojoawo (2020).

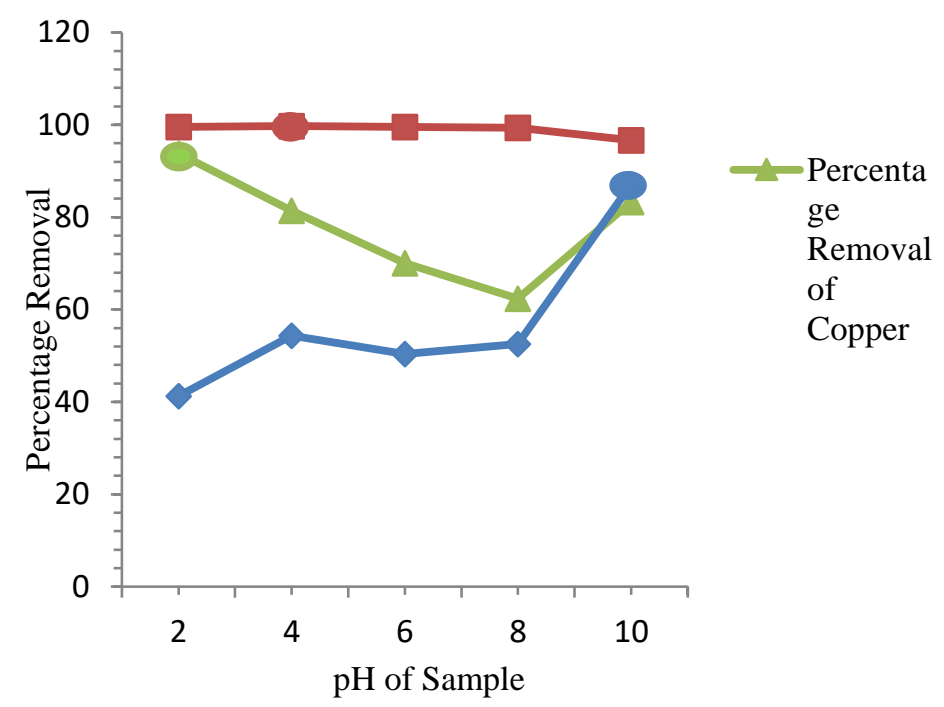

Figure 5. Effect of $\mathrm{pH}$ on percentage removal of Colour, Zinc and Copper

\section{Adsorption Isotherms}

The values of the constants of the two isotherms, namely Langmuir and Freundlich were given in Table 1.

Table 1. The Values of Constants for the Two Adsorption Isotherms

\begin{tabular}{lllllll}
\hline \multirow{2}{*}{ Constants } & Colour & \multicolumn{3}{c}{ Zinc } & \multicolumn{3}{c}{ Copper } \\
\cline { 2 - 7 } & Langmuir & Freundlich & Langmuir & Freundlich & Langmuir & Freundlich \\
\hline $\mathrm{qm} /(1 / \mathrm{n})$ & -19.84 & 2.1263 & 1.1121 & -0.5089 & -17.57 & 1.3473 \\
$\mathrm{~K}_{\mathrm{L}} / \mathrm{K}_{\mathrm{f}}$ & -2.864 & 991.06 & -2997.3 & 0.8362 & -4.948 & 377.22 \\
$\mathrm{R}^{2}$ & 0.5193 & 0.5827 & 0.4418 & 0.6464 & 0.3804 & 0.1721 \\
\hline
\end{tabular}

Langmuir Isotherm model: The results obtained from Langmuir isotherm model for colour, zinc and copper with the plot of 1/qe against 1/Ce are summarized in Figure 6. Equations of straight lines were obtained. Constants $\mathrm{q}_{\mathrm{m}}$ and $\mathrm{K}_{\mathrm{L}}$ were calculated by using equation 3 and results have been tabulated in Table 1. In order to find efficiency of adsorption process, separation factor $\left(R_{L}\right)$ was calculated using equation 4 . The $\mathrm{R}_{\mathrm{L}}$ values for colour, zinc and copper were 11.973, 0.0 and 0.0 , respectively. The value of $R_{L}$ for colour confirms that the adsorption is unfavourable since it is greater 1. Meanwhile, the value of $\mathrm{R}_{\mathrm{L}}$ for the zinc and copper confirms that the adsorption is irreversible (Chen and Zhao 2009; Farooq et al., 2010).

Freundlich Isotherm model: For Freundlich isotherm, the equilibrium data obtained was plotted between $\log$ qe versus Log Ce. The plot of Log qe versus Log Ce gives straight line graphs with correlation coefficients (Figure 7). Constants $\mathrm{K}_{\mathrm{f}}$ and $1 / \mathrm{n}$ were calculated by using equation 5 . The values of $1 / \mathrm{n}$ for colour, zinc and copper were $2.1263,-0.5089$ and 1.3473 , respectively. The value of $1 / \mathrm{n}$ for colour and copper being above one indicates a cooperative adsorption through physical 
LAUTECH Journal of Civil and Environmental Studies

Volume 6, Issue 2; May, 2021

process) (Matouq et al., 2015). On the other hand, the value of $1 / \mathrm{n}$ for zinc tends toward zero; hence, it depicts an irreversible adsorption (Ghasemi and Gholami, 2014).
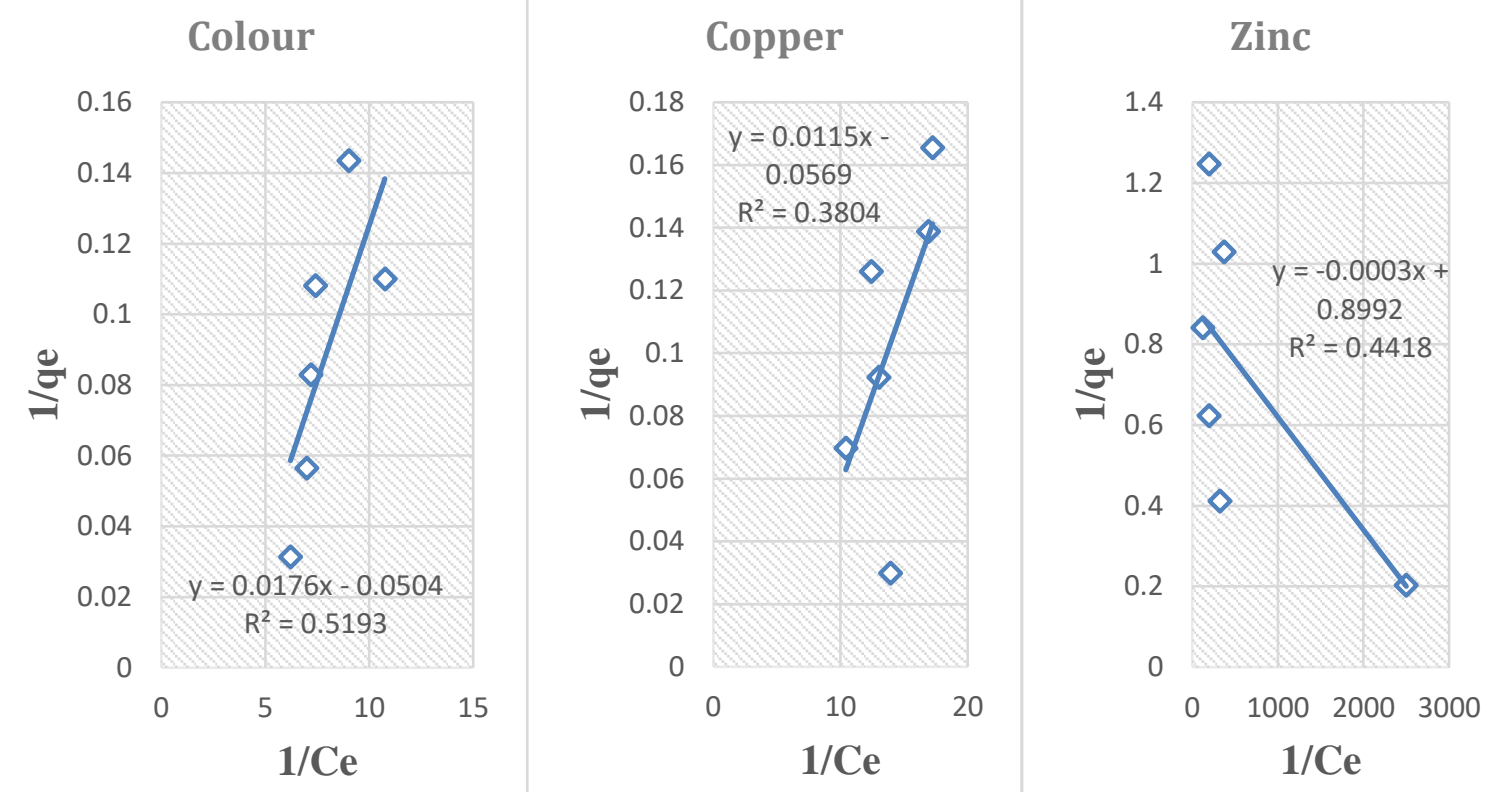

Figure 6. Langmuir isotherm model for Colour, Zinc and Copper adsorption

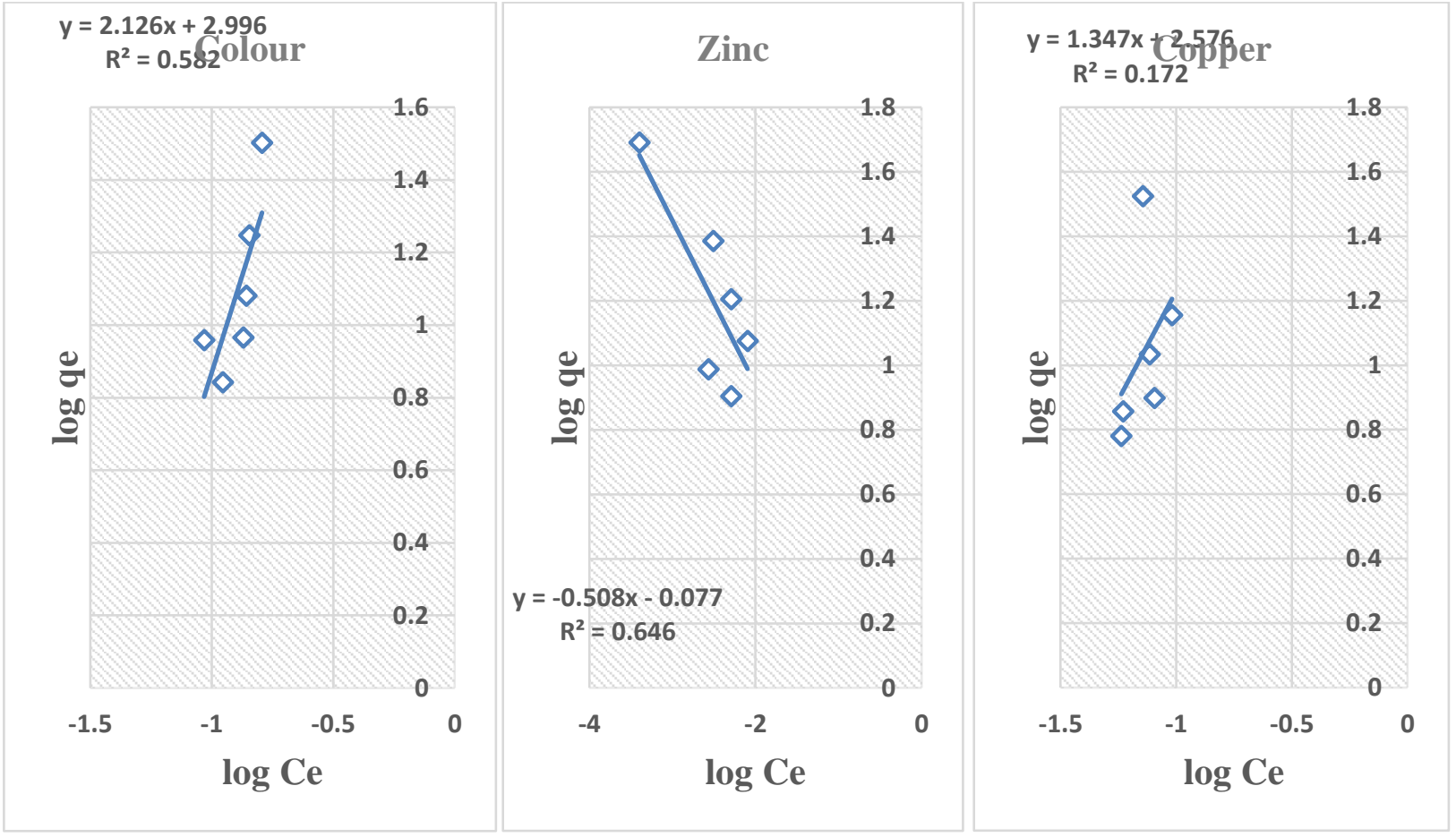

Figure 7. Freundlich isotherm model for Colour, Zinc and Copper adsorption

Generally, the results of colour and zinc removal showed higher correlation coefficient $\left(\mathrm{R}^{2}\right)$ values for the Freundlich model, which confirmed better fitting of this model to the experimental data. Meanwhile, the results of copper removal showed the higher correlation coefficient $\left(\mathrm{R}^{2}\right)$ values for the Langmuir isotherm model, which confirmed better fitting of this model to the experimental data. The lower value of correlation coefficient in either case could be suggested that either of these 
models did not accurately describe the correlation between the amounts of adsorbed colour or metal ions and their equilibrium concentrations in the solutions (Pandey et al., 2017). Roshan (2015) has also investigated removal of Congo red dye from water using orange peel as an adsorbent and found Freundlich isotherm model a better fit in the adsorption isotherm model. Fitting of data to Freundlich model shows that adsorption of the dye follows heterogeneous polylayer coverage of the adsorbate on the adsorbent surface (Freundlich and Heller, 1939) and to Langmuir isotherm model indicates that the adsorbent surface is uniform and homogeneous and that the adsorption reaction results in the formation of a monolayer of adsorbed molecules (Langmuir, 1918).

\section{Adsorption kinetics}

This reflects the relationship between rate of sorption and contact time. The values of $K_{1}$ and $K_{2}$ as subjected to the pseudo first and second order kinetic model were obtained from the slopes of the plot of Log (qe - qt) versus ' $t$ ' (Figure 8) and't/qt' versus 't' (Figure 9) respectively. Equations of straight lines were obtained and the constants $\left(\mathrm{K}_{1}, \mathrm{~K}_{2}\right.$ and $\left.\mathrm{q}_{\mathrm{e}}\right)$ were calculated using equation 7 and 8 respectively. The results show that the values of correlation coefficients $\left(R^{2}\right)$ from the pseudo-first order kinetic model were low compared to the pseudo-second order kinetic model, which suggested that the adsorption of both colour and metal ions departed significantly from the pseudo-first order kinetic model and could not explain the adsorption mechanism of colour, zinc and copper onto the carbonised orange peels. These results indicated that the adsorption system studied followed the pseudo-second order kinetic model for both colour and metals, with correlation coefficient in both cases being close to one. The pseudo-second order kinetic mode was based on the fact that chemical sorption controls the sorption rate (Ding et al., 2011). If kinetic model fits well to pseudo-second order reaction plot by giving $\mathrm{R}^{2}$ value close to one, it indicates an inclination towards chemisorption.

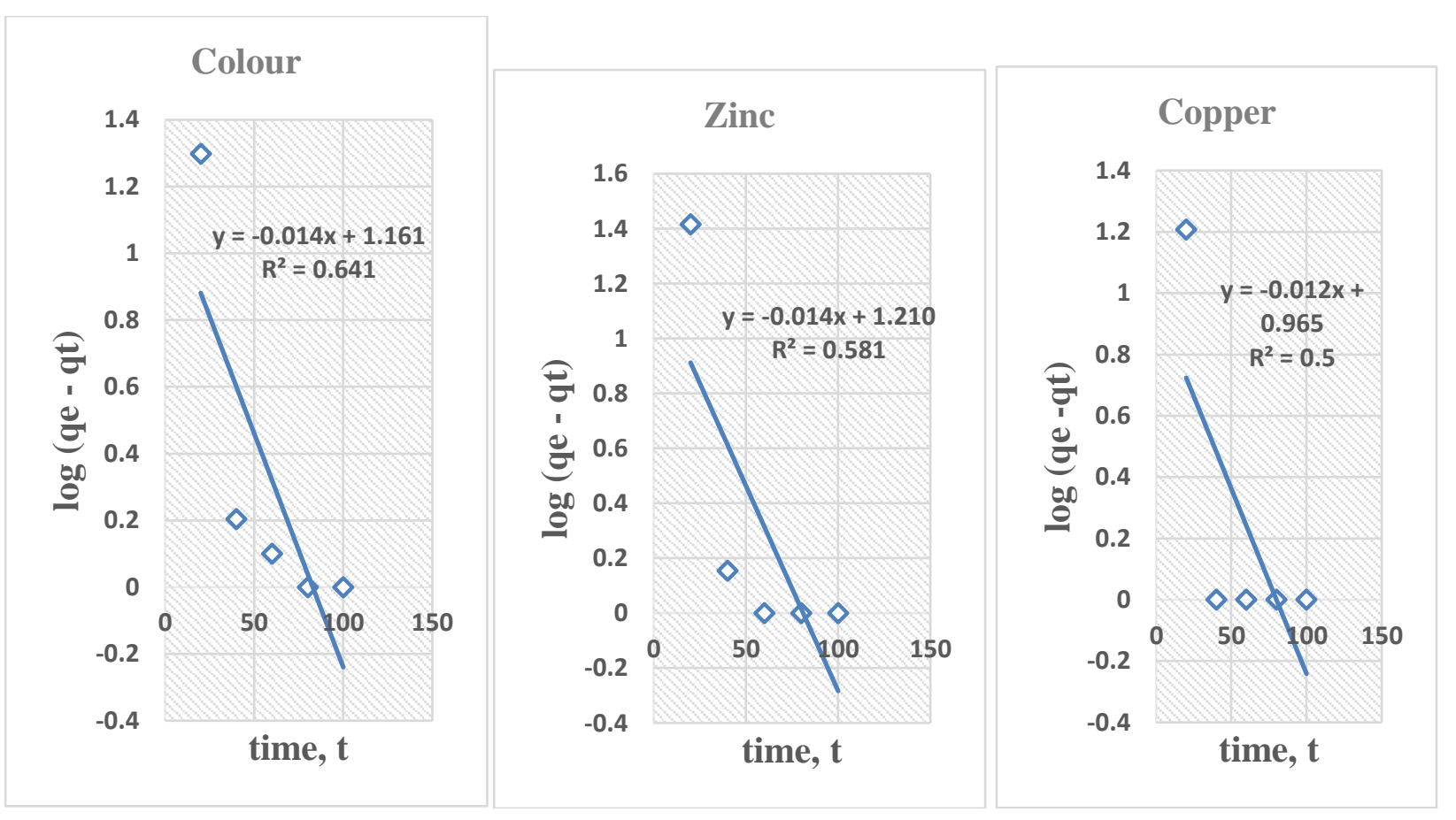

Figure 8. Pseudo-first order model simulation of colour, zinc and copper by the carbonized orange peel 
LAUTECH Journal of Civil and Environmental Studies

Volume 6, Issue 2; May, 2021

However, if pseudo-first order reaction plots by giving $\mathrm{R}^{2}$ value close to unity, it indicates that the reaction is more inclined towards physisorption. Meanwhile Ojoawo and Udayakumar (2016) found pseudo-second order fit for the remediation and adsorption studies of $\mathrm{Pb}^{2+}$ and $\mathrm{Cu}^{2+}$ in fresh foundry wastewater using AC-250 on the basis of higher $\mathrm{R}^{2}$. Again, Matouq et al., (2015) investigated adsorption kinetics and modelling for heavy metal removals and found pseudo-second order fit for it on basis of higher $\mathrm{R}^{2}$.

Table 2 summarizes the general findings from this adsorption study of Orange Peel on textile dye wastewater.

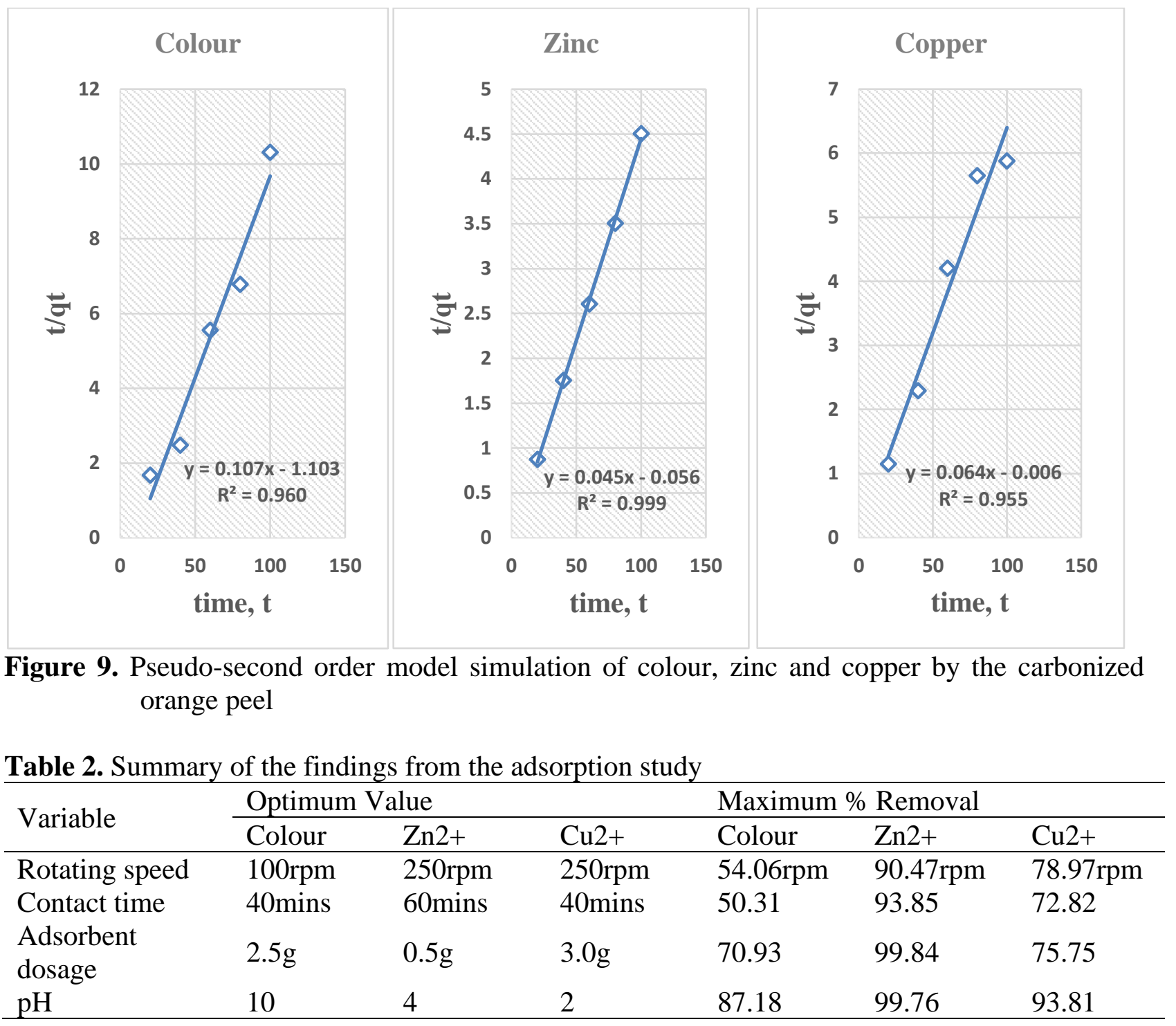

\section{Conclusion}

Carbonized orange peel (COP), an agro waste shows significant adsorption capacity for the remediation of colour from textile wastewater. Moreover, the carbonized orange peel was also most efficient in the removal of $\mathrm{Zn}^{2+}$ and $\mathrm{Cu}^{2+}$ under standard parameters and suitable experimental conditions. The study concludes as follows:

i. Carbonized orange peel is highly effective in the remediation of colour, $\mathrm{Zn}^{2+}$ and $\mathrm{Cu}^{2+}$ from textile wastewater. Orange peels being readily available at no or low cost can be carbonized and serve as a suitable cheap and environmentally friendly adsorbent in colour and metal ions' removal from textile wastewater 
ii. Adsorption isotherms suggest that only the copper adsorption is optimum and fits well with Langmuir isotherm

iii. The adsorption behaviour of both the colour and the metal ions was best demonstrated by kinetic model of pseudo-second order with high correlation coefficient

iv. Moreover, the study outcome can also be valuable for designing and devising a frugally lowcost treatment process plant for the remediation of dyes and trace metals of wastes from industries.

Carbonized orange peel (COP) is therefore recommended as an adsorbent for textile wastewater's treatment before discharging into the environment. It could be employed as a substitute to the costly commercial adsorbents for the colour and trace metals' removal.

\begin{tabular}{|c|c|}
\hline \multicolumn{2}{|c|}{ Nomenclatures } \\
\hline$C_{e}$ & equilibrium concentration after adsorption, $\mathrm{mg} / \mathrm{L}$ \\
\hline$C_{0}$ & concentration before adsorption, $\mathrm{mg} / \mathrm{L}$ \\
\hline$K_{1}$ and $K_{2}$ & $\begin{array}{l}\text { the adsorption rate constants of pseudo-first-order and } \\
\text { pseudo-second-order kinetic models }\end{array}$ \\
\hline$K_{f}$ & $\begin{array}{l}\text { Freundlich constant related to adsorption intensity of } \\
\text { Adsorbents, } \mathrm{mg} / \mathrm{g}\end{array}$ \\
\hline$K_{L}$ & $\begin{array}{l}\text { Langmuir isotherm constant associated with energy of } \\
\text { Adsorption }\end{array}$ \\
\hline$n_{f}$ & Freundlich exponent \\
\hline$q_{e}$ & adsorbed concentration at equilibrium, $\mathrm{mg} / \mathrm{g}$ \\
\hline$q_{m}$ & $\begin{array}{l}\text { maximum capacity of adsorbent for adsorbate corresponding } \\
\text { the complete monolayer coverage, } \mathrm{mg} / \mathrm{g}\end{array}$ \\
\hline$R^{2}$ & correlation coefficient \\
\hline $1 / n$ & a measure of adsorption intensity (ranges between 0 and 1) \\
\hline \multicolumn{2}{|c|}{ Abbreviations } \\
\hline $\mathrm{AC}-250$ & Activated Carbon grade 250 \\
\hline AAS & Atomic Absorption Spectrophotometer \\
\hline BOD & Biochemical Oxygen Demand, mg/l \\
\hline COD & Chemical Oxygen Demand, mg/l \\
\hline FTIR & Fourier Transform Infrared Spectroscopy \\
\hline $\mathrm{pH}$ & degree of alkalinity or acidity \\
\hline RPM & Revolutions Per Minute \\
\hline
\end{tabular}

\section{References}

Adetoro, E. A. and Ojoawo, S. O. (2020). Efficiency of Carica papaya stem activated with phosphoric acid and sodium hydroxide in mining wastewater treatment. Proceedings of Conference on Civil Engineering Trends and Challenges for Sustainability (CTCS-2020) under International Conference on Emerging Trends in Engineering (ICETE-2020), NMAM Institute of Technology, Nitte, Karnataka, India on 22nd \& 23rd of December, 2020.

Ahmad, M. A., Ahmed, N., Adegoke, K. A. and Bello, O. S. (2020). Trapping synthetic dye molecules using modified lemon grass adsorbent. Journal of Dispersion Science and Technology, DOI: $10.1080 / 01932691.2020 .1844016$. 
LAUTECH Journal of Civil and Environmental Studies

Volume 6, Issue 2; May, 2021

Ahmad, M. A., Ahmed, N. B., Adegoke, K. A. and Bello, O. S. (2021). Adsorptive potentials of lemon grass leaf for methylene blue dye removal. Chemical Data Collections, 31, 100578.

Akinhanmi, T. F., Ofudje, E. A., Adeogun, A. I., Aina, P. and Ilo, M. J. (2020). Orange peel as lowcost adsorbent in the elimination of $\mathrm{Cd}$ (II) ion: kinetics, isotherm, thermodynamic and optimization evaluations. Bioresources Bioprocess, 7(34), 2.

Allen, S. J. and Koumanova, B. (2005). Decolourisation of water / wastewater using adsorption (Review). J. Univ. Chem. Technol. Metallurgy, 40(1), 175.

Alyuz, B. and Velis, S. (2009). Kinetics and equilibrium studies for the removal of nickel and zinc from aqueous solution by ion exchange resins. Journal of Hazardous Material, 167(1), 482 - 488.

AsmaHanif, H., Nawaz, B. and Muhammad, A. (2009). Removal and recovery of Cu(II) and Zn(II) using immobilized menthaarvensis distillation waste biomass. Journal of Bioresource Technology, 35(1), 1427 - 1434.

Baban, A., Yediler, A., Lienert, D., Kemerdere, N. and Kettrup, A. (2003). Ozonation of high strength segregated effluents from a woollen textile dyeing and finishing plant. Dyes Pigments, $58,93$.

Bello, O. S., Adegoke, K. A., Sarumi, O. O. and Lameed, O. S. (2019). Functionalized locust bean pod (Parkia biglobosa) activated carbon for Rhodamine dye removal. Heliyon, 5(8).

Benaissa H. (2006). Screening of new sorbent materials for cadmium removal from aqueous solutions. Hazard Material, 132(1), 189 - 195.

Chen, H. and Zhao, J. (2009). Adsorption study for removal of Congo red anionic dye using organoattapulgite. Adsorption, 15 (4), $381-389$.

Ding, Y., Jing, D. B., Zhou, L. B., Yang, X. S. and Wu, Y. J. (2011). The adsorption of aquatic cadmium (II) by chesnut inner shell. Acta. Sci. Circum., 31(9), 1933 - 1941.

Dos Santos, W. N. L., Cavalcante, D. D., Da Silva, E. G. P., Das Virgens, C. F. and Diasm F. D. S. (2011). Biosorption of $\mathrm{Pb}$ (II) and Cd (II) ions by Agave sisalana (sisal fiber). Microchemical J., 97(1), $269-273$.

Farooq, U., Kozinski, J. A., Khan, M. A. and Athar M. 2010 Biosorption of heavy metal ions using wheat-based biosorbents - a review of the recent literature. Bioresources Technology, 101(1), 5043 - 5053.

Farhan A. M., Salem, N. M., Al-Dujail, A. H. and Awwad, A. M. (2012). Biosorption of Cr (VI) ions from electroplating wastewater by walnut shell powder. American Journal of Environmental Engineering, 2(6): 188-195.

Freundlich, H. and Heller, W. (1939). The adsorption of Cis- and transzaobenzene. Journal of American Chemical Society, 61(1), 2228 - 2230.

Garg, V. K., Amita, M., Kumar, R. and Gupta, R. (2004). Basic dye (methylene blue) removal from simulated wastewater by adsorption using Indian rosewood sawdust: a timber industry waste. Dyes Pigment, 63(1), 243 - 250.

Ghasemi, S., and Gholami, R. M. (2014). Copper removal by eucalyptus sawdust and determination of isotherms and kinetics of adsorption process. Journal of Advances in Env. Biology, 8(21), 105 - 113.

Gonen, F., and Serin, D. S. (2012). Adsorption study on orange peel: removal of Ni (II) ions from aqueous solution. African Journal of Biotechnology, 11(5), 1250 - 1258.

Hassan, A. O. and Abiola, J. T. (2018). Adsorption and Desorption of $\mathrm{Pb}^{2+}$ using Orange Peel Activated Carbon (OPAC) in the Remediation of Metal Galvanizing Industrial Wastewater. B.Tech. Project Report, Department of Civil Engineering, Ladoke Akintola University of Technology, Ogbomoso.

Hatch, K. L. (2003). Textile dyes as allergic contact allergens. Elser P, Hatch K, Wigger- Aberti W(eds): Textile and skin. Curr. Probl. Dermatol. Basel, Kerger, 31(1), 139 - 155.

Javaid, M. (2013). Dye fixation and decolouration of vinyl reactive dyes by using dicyanidiamide fixer in the presence of ferric chloride. Journal of Saudi Chemical Society. 17(1), 23-28. 
Lee, D. W., Hong, W. H. and Hwang, K. Y. (2000). Removal of an organic dye from water using a predispersed solvent extraction. Sep. Sci. Technol., 35(1), 1951.

Liang, S., Guo, X., Feng, N. and Tian, Q. (2010). Isotherms, kinetics and thermodynamics studies of adsorption of $\mathrm{Cu}^{+2}$ from aqueous solutions by $\mathrm{Mg}^{+2} / \mathrm{K}^{+}$type orange peel adsorbents. Journal of Hazardous Material, 174(1-3), 756 - 762.

Langmuir, I. (1918). The adsorption of gases on plane surfaces of glass, Mica and Platinium. Journal of American Chemical Society, 40(1), 1361 -1403.

Lohani, M. B., Singh, A., Rupaiwar, D. C. and Dhar, D. N. (2008). Studies on efficiency of guava (Psidiumguajava) bark as bioadsorbent for removal of $\mathrm{Hg}$ (II) from aqueous solutions. Journal of Hazardous Materials, 159(1), 626-629.

Malik, P. K. (2004). Dye removal from wastewater using activated carbon developed from sawdust: adsorption equilibrium and kinetics. Journal Hazardous Material, 113 (1-3), 81 - 88.

Markandeya, S., Shukla, P. and Kisku G. C. (2015). Linear and non - linear kinetic modelling for the adsorption of disperse dye in a batch process. Research Journal of Environmental Toxicology, doi: 10.3923/rjet.2015.

Matouq, M., Jildeh, N., Qtaishat, M. Hindeyeh, M. and Syouf, M. Q. A. (2015). The adsorption kinetics and modelling for heavy metals removal from wastewater by moringa pods. Journal of Environmental Chemical Engineering, 3(2), 775 - 784.

Mohan, N., Balasubramanian, N. and Basha, C. A. (2007). Electrochemical oxidation of textile wastewater and its reuse. Journal of Harzadous Material, 147(1), 644.

Noorozi, B. and Sorial, G. (2013). Applicable models for multi - component adsorption of dyes: A review. Journal of Environmental Sciences, 25(3), 419 - 429.

Ojoawo, S. O., Adegbola, A. A., Olaniyan, O. S., Olaoye, R. A., Oluremi, J. R., Ajamu, S. O., and Ademola, I. A. (2018). Performance evaluation of Azardirachta Indica (Neem Tree) bark in the remediation of $\mathrm{Pb}^{4+}$ and $\mathrm{Cr}^{3+}$ from galvanizing industrial wastewater. The Advances in Multidisciplinary and Scientific (AIMS) Research Journal, 4(2), 73-88.

Ojoawo, S. O. and Udayakumar, G. (2016). Remediation and adsorption studies of $\mathrm{Pb}^{2+}$ and $\mathrm{Cu}^{2+}$ in fresh foundry wastewater using Activated Charcoal-250. Advances in Multidisciplinary Research Journal, 2(3), 67-82.

Pandey, S. S., Singh, N. B., Shukla, S. P. and Markandeya, T. (2017). Removal of Lead and Copper from Textile Wastewater using Egg Shells. Iranian Journal of Energy and Environment, 8(3), $202-209$.

Pereira, M. G. and Arruda, M. A. Z. (2003). Vermicompost as a natural adsorbent material: characterization and potentialities for cadmium adsorption. Journal of Brazillian Chemical Society, 14(1), 39-47.

Roshan, K. S. (2015). Removal of congo red dye from water using orange peel as an adsorbent. www.semanticscholar.org (accessed June 2, 2019).

Salem, I. A. (2001). Activation of $\mathrm{H}_{2} \mathrm{O}_{2}$ by Amberlyst-15 resin supported with copper(II)-complexes towards oxidation of crystal violet. Chemosphere, 44(1), 1109.

Salleh, M. A., Mahmoud, D. K., Abdul-Karim, W. A. and Idris A. (2011). Cationic and anionic dye adsorption by agricultural solid wastes: A comp. review. Desalination, 280(1), 1- 13.

Shinde, N. R., Bankar, A.V., Kumar, A. R. and Zinjarde, S. S. (2012). Removal of Ni (II) ions from aqueous solutions by biosorption onto two strains of Yarrowia lipolytica. Journal of Environmental Management, 102(1), 115 - 124.

Shinde, N. R., Bankar, A.V., Kumar, A. R. and Zinjarde, S. S. (2012). Removal of Ni (II) ions from aqueous solutions by biosorption onto two strains of Yarrowia lipolytica. Journal of Environmental Management, 102(1), 115 - 124.

Sivaraj, R., Namasivayam, C. and Kadirvelu, K. (2001). Orange peel as an adsorbent in the removal of acid violet 17(acid dye) from aqueous solutions. Waste Management, 21 (1), 105 - 110. 
Tanaka, K., Padermpole, K. and Hisanaga, T. (2000). Photocatalytic degradation of commercial azo dyes. Water Res., 34(1), 327.

Vandevivere, P. C., Bianchi, R. and Verstaete, W. (1998). Review: Treatment and reuse of wastewater from the textile wet-processing industry: Review of emerging technologies. $J$. Chem. Technol. Biotechnol., 72(1), 289.

Yu, Y., Zhuang, Y. Y. and Wang, Z. H. (2001). Adsorption of water-soluble dye onto functionalized resin. J. Colloid Interface Sci., 242(1), 288.

Zhou, W., Zhang, H., Ma, Y., Zhou, J., and Zhang, Y. (2013). Bio-removal of cadmium by growing deep-sea bacterium Pseudoalteromonas sp. SCSE 709 - 6, Extremophiles. 